\title{
Speech content analysis of male and female L2 teachers in Iranian EFL context
}

\author{
Attaran, Atena \\ Ferdowsi University of Mashhad, Iran (atena.attaran@gmail.com) \\ Morady Moghaddam, Mostafa $\bowtie$ \\ Young Researchers Club, Mashhad Branch, Islamic Azad University, Mashhad, Iran \\ (mostafa_morady@yahoo.com)
}

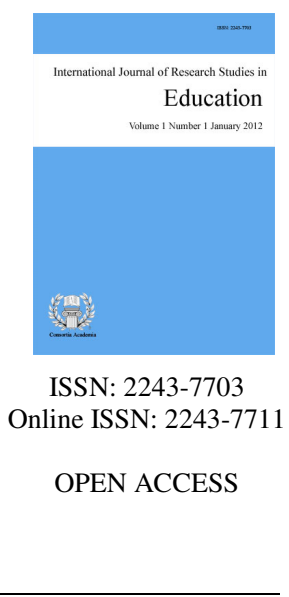

\section{Abstract}

This study aimed at investigating the speech content of male and female teachers in the context of Iranian EFL classes. Previous studies on speech content are mainly conducted on European cultures and there is a niche considering investigations of gender differences in Iranian EFL context with regard to speech content. To this end, 74 EFL classes were observed to figure out the quality of speech content in different genders among teachers. After observing the classes and recording teachers' voices, their speech was transcribed. The content of the transcribed texts was counted based on the Linguistic Inquiry and Word Count (LIWC) principles. The data were analyzed according to Newman, Groom, Handelman, and Pennebaker' (2008) word-count model. Four categories were investigated to find out the gender differences among male and female teachers. The categories are linguistic dimensions, prepositions, psychological processes, and pronouns. The results revealed significant differences among male and female teachers considering various categories of speech content. The Chi-square formula was utilized to investigate the frequencies.

Keywords: speech content; gender differences; word count; teacher interaction; corpus 


\section{Speech content analysis of male and female $\mathbf{L} 2$ teachers in Iranian EFL context}

\section{Introduction}

To pave the way toward the discussion of speech content analysis and its importance, we began our journey by quoting the words of Otto Jesperson (1921):

In primitive speech I hear the laughing cries of exultation when lads and lassies vied with one another to attract the attention of the other sex, when everybody sang his merriest and danced his bravest to lure a pair of eyes to throw admiring glances in his direction. Language was born in the courting days of mankind (cited in Yule, 1996, p. 1).

Gender has a great influence on different aspects of human life including language learning and general education. In the other hands, gender provides a worldview for individuals to admire, complain, suggest, criticize, annoy, and it has vital influence on every aspect of human communication. As far as men are from Mars, and women from Venus, the way they use language differs both in writing and speaking.

The nature and existence of these differences were subject to many studies in recent decades. The findings suggested that in some languages penetration of gender was just at the level of vocabulary and expression while in other, it entered the realm of grammatical structures as well. To make it more clearly, for example, pronouns in Persian language are not sensitive to gender while in some languages such as Arabic and French they are.

Other studies such as Ferber (1995) showed that while reading a transcribed text, speaker's gender could be easily identified in many cases because gender is context dependent. For instance, men are generally supposed to talk about technical issues more than women do.

To take the context into account, it is necessary for applied linguistics and educators to investigate gender in the context of language teaching classrooms. Teachers as facilitators, counselors, and conductors of knowledge symphony play significant roles in the classrooms. This paper tried to manifest speech differences in L2 male and female teachers.

\section{Review of Literature}

The seminal work of Jesperson (1992), Language: Its Nature, Development and Origin, created a yardstick for researchers and teachers to investigate gender differences in language classes based on the speech content and language use. Jesperson claimed that men's language is standard while women's is a deviant form. He mentioned a long list of different vocabularies which were used by men and women and he concluded that women had limited vocabularies in comparison to men. Later this idea was criticized by Lakoff. She believed that women were socialized or in better words, trained since childhood to be ladylike. She saw the reason as power is in the hands of men and their discourse.

The puzzle got more complex when in 2001, Mulac, Bradac, and Gibbons (2001) studied on "Intercultural Analysis of Male/Female Language Difference" and concluded that:

Boys and girls learn to use language from models provided by members of their respective in-groups; accordingly cross-group (out-group) differences in power are not pertinent in learning gender-specific language modes and styles... Boys and girls may share a common vocabulary but use that vocabulary in dissimilar ways (p. 122).

Politeness is another feature in gender language which is hardly in contact with society and social training. Freemen and McElhinny (1996) believed that "in societies where directness and politeness is seen as a form of 
deference rather than a skill women tend to be more polite or are perceived as more polite" (p.251).

Despite the fact that some differences exist in men and women languages, their languages are not totally different. Sukegawa (1998) believed that the two languages differ mostly according to terminology, pronunciation, and pronouns. However, they were not different according to grammatical structures or word order. In order to make it more clear, the article reviewed the previous researches on different aspects of gender as followed:

I) Gender and Textbooks

II) Gender and Writing

III) Gender and Pronunciation

IV) Gender and Speaking

\subsection{Gender and Textbooks}

Rifkin (1998) in a case study of 12 popular textbooks of Russian for the high school and college classroom, including first-year textbooks and second-year or intermediate-level textbooks tried to find out:

a) Recent textbooks were more equitable in gender than textbooks published 10 or 20 years ago.

b) Textbooks written by women or by a team of authors including at least woman would be more equitable in terms of gender representation than textbooks written only by men.

The findings showed that newer textbooks are not necessarily unbiased in gender representation, but some of the new ones are among the most impartial books. Moreover, presence or absence of a woman in authorship group did not guarantee the textbook equitability in gender. In addition to these facts, he came to the conclusion that gender representation in textbooks affected learning process.

Another study by Sunderland (2000) on textbooks, confirmed that in content analysis of textbooks, male figures were demonstrated as more powerful figures and they were overpresented in textbooks. Women mostly had marginal roles and were pictured as emotional, motherly-like members of society. She claimed this unbiased representation would influence students learning but it is hard to prove it.

\subsection{Gender and Writing}

Gender seemed to influence writing style as well. As soon as modern technology walks into people's life, pen and pencils left the scene and keyboard appeared as the aftermath of the technological innovations. This was how e-mail communication emerged by net pals. So far, Colly and Todd (2002) tried to investigate the content and style of males and females in e-mail communication. Therefore two hypotheses were tested:

a) Does e-mail communication differ to same or opposite-sex friends in stylistic features?

b) Do the e-mail topics vary due to the senders' gender?

The participants in this study were 24 male and 30 female undergraduate students, with a mean age of 20.4 years. Their background information showed that there was no gender differences in frequency of computer use, however, males received and sent more e-mails than females. They were supposed to write an e-mail to a male or female friend who were interested to spend his/her holiday where they recently have been. The results showed that "the rate of occurrence and word count data were analyzed using 2 X 2 (sex of sender X sex of recipient) ANOVAs. No significant effects emerged from the ANOVA of word count (p. 386). It was also found that women used more exclamation marks, they asked more questions and gave more warnings. The interesting point was that men and women sender made more self-disclosure to opposite sex rather than the same-sex. Moreover it was revealed that female senders used trivial points in e-mails to men (mean rate $=0.62$ ) than to women (mean rate $=0.12$ ). 
The e-mails content analysis manifested that shopping, cost, and night life where among those topics discussed by women while men mostly talked about holiday location and local people.

Another study was undertaken by Thomson, Murachver, and Green (2001) examined how males and females adapt themselves to the gender preferential language in e-mail communication. Two experiments were designed. In the first experiment the total of 22 undergraduate psychology students ( 11 females, 11 males) with a mean age of 21.1 years were asked to write e-mails to two net pals, while both were one of the experimenters. For each participant one of the net pals named Jane and the same net pal would be called Peter as well. The results showed that participants in this study changed their writing style due to the receiver's gender; their own gender had nothing or little to do with their writing style.

In order to see whether participants adopted themselves to gender-preferential styles or gender labels, another experiment was done. In this one, 65 undergraduate psychology students ( 33 females, 32 males; mean age $=21.2$ years) participated. This time each was paired with one net pal either a female/male label or a female/male-preferential language style. MANOVA was calculated and revealed that participants' language use was a result of both their own gender and style used by their net pals.

\subsection{Gender and Pronunciation}

Sukegawa (1998) paid the close attention to men and women pronunciation which is worth mentioning. Observations and tests were the instruments which helped him to claim that women tried to speak in a way closer to accepted standard and they liked to seem prestigious whereas men preferred to deviate from standard forms.

He could also found differences in intonation and pitch. Due to his observations, men had three contrastive levels of pitch but women had four. As a matter of fact, high pitch is a feature of women's voice. Moreover, polite, cheerful, incomplete sequence and surprise were those of women intonation especially when they talked to children.

\subsection{Gender and Speaking}

Singh (2001) conducted a pilot study of gender differences in conversational speech on lexical richness measures with a total of thirty (13 male and 17 female subjects) who did not suffer any language impairments. Participants were asked about their hobbies, life experiences, current activities, and any other topics they were interested in and they were recorded. In order to analyze the transcribed texts, Oxford Concordance Program (OCP) was used. The analysis showed that male speakers used longer sentence structure than female ones and their speech was lexically richer while repetitive lexical items were more apparent in female speakers' speech.

Gender differences have also been examined by studying the actual words people use. Boulis and Ostendorf (2005) carried out a quantitative research on lexical differences in telephone communication between male and female speakers. Approximately, 10127 conversations were tested by the early version of the Fisher corpus among American native speakers. The conversations were according to a list of 40 topics and the topics were suggested at the beginning of each call. The accuracy was claimed to be close to 93\%. They observed that men swear more, on the other hand, family-relation terms are often related to women. For example, shit, bullshit, damn, goddamn are used mostly by men while children, grandchild, kids, son, mother, marriage are among those used by women. According to Sukegawa (1998), although slang is mostly used by men, women maneuver on the following adjectives more than men: heavenly, cute, divine, adorable, lovely, and pretty. Furthermore, Boulis and Ostendorf (2005) mentioned that non-lexical tokens were in accordance with a certain gender. For instance, laughter and acknowledgement/backchannels* such as $u h$-huh, whuh were more common for females than males , whereas, the reverse is true for filled pauses such as $u h$ because men assume a more dominant role than women

\footnotetext{
* A noise, gesture, expression, or word used by a listener to indicate that he or she is paying attention to a speaker (white, 2003).
} 
in conversations. "Males tend to hold the floor more than women (more filled pauses) and females tend to be more responsive (more acknowledgment/ backchannel)" (p. 440).

Names are the other indicators of gender differences. A possible reason is that people usually introduce themselves at the beginning of their conversations. Boulis and Ostendorf (2005) revealed that males used names in their speech half time more than women did.

Another feature which is mostly labeled to women's way of speaking is the use of tag questions. White (2003) believed that women use tag questions in their speech as a facilitative device which supported the fact that women paid more attention to their interlocutors in their communications, and these tag questions do not weaken women's speech as was mentioned by Jesperson earlier.

\section{Limitation of Previous Researches}

The above mentioned aspects of gender were mostly studied in European countries. Mulac, Bradac, and Gibbons' study on "Intercultural Analysis of Male/Female Language Difference" (2001) with 10 undergraduate students as participants confirmed that men and women's ways of talking represent their culture. Therefore these differences may vary according to speakers' cultures. Consequently, it is necessary for Iranian researches to improve their understanding toward Iranian male and female language differences.

Besides most of the participants in gender researches were students or ordinary people but not language teachers, especially L2 teachers. As a result, this paper devoted itself to L2 teachers who tried to open new horizons for their students.

\section{Method}

\subsection{Participants}

To achieve the purpose of this study, 74 EFL classes were observed to figure out the quality of speech content in different genders among teachers. Teachers had gotten their BA degree in English Teaching as a Foreign Language and Translation Studies. In fact, the target population of this study included all male and female ESL teachers but the accessible population was limited to male and female EFL teachers of Mashhad at different FCE (First Certificate in English) levels. In this study random sampling and cluster sampling were not possible because there were many teachers and institute managers who prefer not to participate in this research.

The FCE levels were chosen due to the fact that teachers in these levels are not supposed to simplify their language as they do in elementary or lower intermediate levels. Moreover, students in these levels are not quite independent to their teachers as they are in advanced levels. The observed classes were held by the average number of six EFL learners. In addition, no bonus payments were paid to the participants.

\subsection{Instrumentation}

In these classes, Ready for FCE book was being taught. It is a book which consists of 15 units. Each three units are supposed to be covered in one term. The book is designed to help students prepare themselves for the Cambridge First Certificate in English Examination. The book contains a wide range of activities and practices in reading, writing, listening, and speaking. Moreover, it includes grammar references, wordlist, and typescripts.

\subsection{Procedure}

To collect data and to attain the goal of the study, the researchers participated in classes and observed the ongoing class procedural. The observational research procedure was used as it was done in the previous researches with related subject of study, such as Sukegawa (1998), Bolis and Ostendorf (2005), or Newman, 
Attaran, A. \& Morady Moghaddam, M.

Groom, Handelman, and Pennebaker (2008). Despite several impediments on the way, 15 sessions were observed and recorded which eight of them were under study. Each session was 90 minutes and 12 hours were analyzed all together.

\subsection{Data Analysis}

After recording the sessions of FCE classes, they were transcribed to answer the main question of this paper which is whether ESL male and female teachers use language differently.

The provide text corpus samples were analyzed in a way as they were in Newman, Groom, Handelman, and Pennebaker (2008). In that study they used the Linguistic Inquiry and Word Count (LIWC). It is a word by word analysis and each word is compared to a two thousands-word-dictionary with 74 linguistic categories. Some of these categories are purely grammatical like articles and some other categories for instance "positive emotion words" are defined based on the independent judges. Here the researchers relied on Newman, Groom, Handelman, and Pennebaker (2008) categorizations. The outcome is presented as a percentage of the word use.

As the context of this study for the teachers was the same, the researchers did not consider the effect of context on language. But an attempt was made to take into the consideration the effect of language differences among learners.

\section{Results and Discussions}

After observing the classes and recording teachers' voices, their speech was transcribed. The words of the provided texts have been counted based on the Linguistic Inquiry and Word Count (LIWC) principles. The mean and percentage of each of the male and female teachers was applied to determine the significance of each. Taking a look at the table demonstrated that there are some discrepancies regarding the frequency of gender differences among male and female teachers.

\section{Table 1}

The Distribution of Gender Differences among EFL Male and Female Teachers

\begin{tabular}{lccccc}
\hline \multicolumn{1}{c}{ Dimensions } & Male & Female & $\begin{array}{c}\text { Expected } \\
\text { Frequency }\end{array}$ & Chi-square & Sig. \\
\hline Linguistic Dimensions & 125 & 163 & 144 & 4.571 & .033 \\
Prepositions & 69 & 91 & 80 & 3.025 & .082 \\
Psychological Process & 113 & 55 & 84 & 20.024 & .000 \\
Pronouns & 51 & 75 & 63 & 4.571 & .033 \\
Total & 358 & 384 & - & - & - \\
\hline
\end{tabular}

As it is revealed in Table 1, there is a significant difference between all the pairs of dimensions except for the prepositions. Male teachers' transcription showed that they used linguistic dimensions more than the other dimensions, however, with a lower distribution in comparison to female one $(n=163)$. This finding brings some questions with itself:

a) Are female classes less communicative than male's?

b) Do female teachers provide more feedback rather than male ones?

c) Do male teachers have a holistic view toward language while female ones pay more attention to details?

This study showed that men asked questions 2.8 times more that women which is in contrast with what Colly and Todd (2002) claimed. They believed that women posed more questions and gave more warnings. In the case of using articles and swearing, previous researches such as Sukegawa (1998) were supported. On the other hand, the research was a successful replication of Sukegawa (1998) for using of positive emotion words 
which was about 1.02 percent.

Newman, Groom, Handelman, and Pennebaker (2008) proposed that men and women use of negative words and sentences were on the same scale while the present study showed that 2.95 percent of a male teachers and 1.92 of a female teachers' speech were negative. This can be a warning for male teachers as they are supposed to provide an emotional environment with positive energy to enhance learning. This is what Mortiboys (2005) tried to manifest in Teaching with Emotional Intelligence. Taking the differences into account, Singh (2001) in his study showed that male speakers used longer sentences. In contrast, this research demonstrated that the words women used in their sentences are more than men.

\section{Conclusions}

Text analysis on word count supported some of the findings of the previous researches such as Sukegawa (1998). On the other hand, some others are rejected like Colly and Todd (2002), Singh (2001), and Newman, Groom, Handelman, and Pennebaker (2008). What is important in the context of classroom, among other things is enhancing learning opportunities for learners. Providing an emotional and friendly environment is of key importance in this way. This is language which can best help individuals to create such environment. The analysis showed that the difference between male and female L2 teachers exist though not many. And it may be concluded that female teachers are more successful in this case as their speech is more emotional and friendly. Furthermore, they use less negative words and sentences. In fact, the target population of this study included all male and female EFL teachers but the accessible population was limited to male and female ESL teachers of Mashhad at different FCE (First Certificate in English) levels.

Although random sampling and cluster sampling were possible, there were many teachers and institute managers who prefer not to participate in this research. Conducting the following research widely with more hours of observation would certainly shed new lights on the speech content on EFL teachers who can exert great influence on the learners' achievement.

\section{References:}

Boulis, C., \& Ostendrof, M. (2005). A quantitative analysis of lexical differences between genders in telephone conversation. Proceedings of the $43^{\text {rd }}$ Annual Meeting of ACL, 435-442.

Colly, A., \& Todd, Z. (2002). Gender-linked differences in the style and content of e-mails to friends. Journal of Language and Social Psychology, 21(4), 380-392. http://dx.doi.org/10.1177/026192702237955

Ferber, R. (1995). Is speaker's gender discernible in transcribed speech? Sex Roles, 32, 209-223. http://dx.doi.org/10.1007/BF01544789

Freeman, R., \& McElhinny, B. (1996) Language and gender. In Mackay, S., \& Hornberger, N. H. (Eds.), Sociolinguistics and Language Teaching (219-269). Cambridge University Press.

Jesperson, O. (1992). Language: Its nature, development and origin. New York: Allen \& Unwin.

Mortiboys, A. (2005). Teaching with Emotional Intelligence. New York: Taylor \& Francis.

Mulac, A., Bradac, J., \& Gibbons, P. (2001). Empirical support for the gender-as-culture hypothesis. Human Communication Research, 27(1), 121-152. http://dx.doi.org/10.1093/hcr/27.1.121

Newman, M., Groom, C., Handelman, L., \& Pennebaker, J. (2008). Gender differences in language use: An analysis of 1400 text samples. Discourse Processes, 45, 211-236. http://dx.doi.org/10.1080/01638530802073712

Rifkin, B. (1998). Gender representation in foreign language textbooks: A case study of textbooks of Russian. The Modern Language Journal, 82, 217-236. http://dx.doi.org/10.1111/j.1540-4781.1998.tb01195.x

Singh, S. (2001). A pilot study on gender differences in conversational speech on lexical richness measures. Literary and Linguistic Computing, 16(3), 251-264. http://dx.doi.org/10.1093/1lc/16.3.251

Sukegawa, H. (1998). Some aspects of women's linguistic behavior in English speech form: A sociolinguistic study. St. Luke's College of Nursing Departmental Bulletin Paper, 7, 62-74. 
Attaran, A. \& Morady Moghaddam, M.

Sunderland, J. (2000). New understandings of gender and language classrooms research: Texts, teacher talk, student talk. Language Teaching Research, 4(2), 149-173.

Thomson, R., Murachver, T., \& Green, J. (2001). Where is the gender in gendered language? Psychological Science, 12(2), 171-175. http://dx.doi.org/10.1111/1467-9280.00329

White, A. (2003). Women's usage of specific linguistic functions in the context of casual conversations: Analysis and discussion. UK: AMF Assignment. 